\title{
RELAÇÃO ENTRE VOZ E QUALIDADE DE VIDA EM PROFESSORES UNIVERSITÁRIOS
}

\section{Relation between voice and life quality for university teachers}

\author{
Emilse Aparecida Merlin Servilha ${ }^{(1)}$, Priscila de França Roccon ${ }^{(2)}$
}

\begin{abstract}
RESUMO
Objetivo: investigar o impacto da voz na qualidade de vida de professores e comparar seus resultados com a avaliação fonoaudiológica. Métodos: participaram 21 professores universitários, $77 \%$ mulheres e $23 \%$ homens, com idade média de 48 anos, que preencheram o protocolo Qualidade de Vida e Voz (QVV), e foram filmados para a avaliação fonoaudiológica nos aspectos corporais e vocais. Resultados: os docentes classificaram suas vozes como boas $(42,85 \%)$, razoáveis $(38,09 \%)$ e muito boa e ruim, igualmente (9,52\%). O Domínio Físico apresentou escore médio de 78,18 , e destaque para a dificuldade em falar alto ou ser ouvido em ambientes ruidosos e ter problemas no trabalho ou desenvolver a profissão por causa da voz. No Domínio Sócio-Emocional o escore médio foi 88,98 e mostrou ansiedade ou frustração por causa da voz. O Domínio Global teve média de 82,61 . Na avaliação fonoaudiológica constataram-se mais vozes adaptadas $(61,90 \%)$ que alteradas $(38,09 \%)$, estas apresentando restrição na projeção e modulação ou rouquidão. A comparação entre a auto avaliação vocal, avaliação fonoaudiológica e qualidade de vida mostrou mais consenso que divergências. Conclusão: conclui-se que o impacto da voz sobre a qualidade de vida foi baixo e que houve coerência entre os resultados do QVV e a avaliação fonoaudiológica, indicando percepção apropriada dos docentes em relação à própria voz. O QVV mostrou ter valor preditivo na relação voz e qualidade de vida e pode ser indicado como um instrumento valioso quando utilizado juntamente com outras estratégias de pesquisa.
\end{abstract}

DESCRITORES: Distúrbios da Voz; Docentes; Qualidade de Vida

\section{INTRODUÇÃO}

Os pesquisadores que têm por objeto de estudo a voz do professor estão em acordo quanto ao fato de que a docência requer uso vocal considerável, e que os professores constituem-se em grupo de risco para os distúrbios vocais ${ }^{1-3}$. Os estudos da área mostram múltiplos olhares no desvelamento de aspectos intervenientes no uso profissional da voz pelo professor como identificação de agentes agressores à voz presentes no ambiente e organização do trabalho ${ }^{4-8}$, ou ainda o desconhecimento vocal ${ }^{9}$, alertando para a necessidade de oferecer capacitação para esse profissional manter a voz saudável.

(1) Fonoaudióloga; Docente da Faculdade de Fonoaudiologia da Pontifícia Universidade Católica de Campinas, PUCCAMP, Campinas, SP; Doutora em Ciências pela Pontifícia Universidade Católica de Campinas.

(2) Fonoaudióloga.

Conflito de Interesses: Inexistente
Mais recentemente, possivelmente norteados pelos princípios da Promoção da Saúde ${ }^{10}$, surgem estudos interessados em avaliar o impacto da voz sobre a qualidade de vida. No bojo desta proposta, a saúde passa a ser entendida como estratégia fundamental que impulsiona o desenvolvimento social, econômico e pessoal, e um parâmetro para a determinação da qualidade de vida. A saúde não é um objetivo em si, mas um recurso essencial para a vida cotidiana ${ }^{11}$. Dispor de condições, inclusive vocais, para trabalhar, obter renda para viver dignamente e sentir-se produtivo são considerados pré-requisitos para a saúde ${ }^{12}$. Desta forma, saúde e qualidade de vida mantêm relação complementar.

Qualidade de Vida foi definida pela Organização Mundial da Saúde como "a percepção do indivíduo sobre a sua posição na vida, no contexto da cultura e dos sistemas de valores nos quais ele vive, padrões e preocupações" ${ }^{13}$. E, parece haver um consenso entre os estudiosos da área de que ela abrange aspectos de subjetividade e multidimensio- 
nalidade. A subjetividade diz respeito à auto-avaliação do individuo sobre sua condição pessoal nas diferentes esferas vinculadas à qualidade de vida. Já na multidimensionalidade há o acordo de que o construto é integrado por diversas dimensões, mais especificamente a área física, psicológica, relacionamento social e do ambiente.

Especificamente em relação à área fonoaudiológica, destaca-se a comunicação e a voz, como um domínio extra na avaliação da qualidade de vida, pelo seu papel crucial no exercício laboral, como é o caso dos professores, embora esses profissionais nem sempre percebam as consequências negativas sobre sua qualidade de vida quando apresentam distúrbios da voz. Assim, nas ações fonoaudiológicas em saúde do docente deve-se priorizar a saúde e sua promoção, abrangendo os aspectos do cotidiano e da qualidade de vida que se relacionam à voz, uma vez que ela é inerente aos processos de socialização humana ${ }^{14}$.

O inventário americano Voice Related Quality of Life (V-RQOL) ${ }^{15}$ foi adaptado para a realidade brasileira e ficou conhecido como Questionário de Qualidade de Vida e Voz (QVV) ${ }^{16}$. Ele foi utilizado como um dos instrumentos de pesquisa, para averiguar aspectos da qualidade de vida, voz e subjetividade em professores de ensino médio ${ }^{17} \mathrm{e}$ os resultados revelaram que, apesar das condições desfavoráveis de vida e trabalho, o impacto negativo da voz sobre a qualidade de vida foi baixo, segundo os professores. Em outro estudo com 120 professores do ensino fundamental de escolas públicas ${ }^{18}$, o QVV mostrou que $49,2 \%$ dos docentes avaliaram suas vozes como boa; $24,1 \%$ como muito boa ou excelente e $26,7 \%$ como razoável ou ruim. Apesar da auto-avaliação positiva dos professores, muitos deles mencionaram dificuldades para usar a voz em ambientes ruidosos, assim como coordenar respiração e fonação. Os dados de ambas as pesquisas aparentemente incoerentes levaram as autoras a suspeitarem de uma limitação na auto-avaliação vocal dos professores, assim como em perceberem a relação entre voz e qualidade de vida nas relações laborativas.

É nesse contexto que envolve a voz, a docência e a qualidade de vida que se insere a presente proposta de pesquisa, que teve como objetivos investigar o impacto da voz na qualidade de vida de professores e comparar seus resultados com a avaliação fonoaudiológica.

\section{MÉTODOS}

Integraram nesta pesquisa 21 professores universitários de diferentes áreas do conhecimento, sendo $16(77 \%)$ do sexo feminino e cinco $(23 \%)$ do masculino. A idade dos sujeitos variou de 24 a 73 anos, com média de 48 anos. Eles estavam inscritos em um curso sobre voz na docência oferecido pela pesquisadora.

Os sujeitos foram convidados a participar no primeiro dia do curso anteriormente referido, ocasião em que foram explanados os objetivos da pesquisa e dos instrumentos a serem utilizados. Aqueles que concordaram assinaram um Termo de Consentimento Livre e Esclarecido.

\section{Protocolo QVV}

Foi solicitado aos sujeitos o preenchimento do Protocolo QVV, que se baseia na subjetividade do professor, e atribui uma nota para cada questão numa escala de 0 a 5 de acordo com sua percepção em relação às diferentes esferas de sua vida.

O QVV é composto por dez itens e averigua a relação qualidade de vida e voz em três domínios - físico, sócio-emocional e global, este último agregando os dois anteriores. É de fácil aplicação e confiável, tendo sido empregado em muitas pesquisas brasileiras.

Após o preenchimento do QVV pelos professores, suas respostas foram organizadas em arquivo Excel e seus dez itens relativos aos domínios foram analisados seguindo o protocolo específico requerido para o instrumento, gerando dados quantitativos. Os domínios já padronizados para o QVV mostram valores em um espectro de 0 a 100 , sendo piores aqueles com a proximidade de zero e melhores aqueles cujos valores se aproximam de 100. Para comparação dos resultados consideraram-se escores de 81-100 como baixo impacto, de 61-80 como médio e menor ou igual a 60 como alto impacto da voz na qualidade de vida ${ }^{17}$.

O domínio sócio-emocional compreende as questões 4 (Fico ansioso ou frustrado por causa da voz), 5 (Fico deprimido por causa da minha voz), 8 (Evito sair socialmente), 10 (Tenho me tornado menos expansivo por causa da minha voz) colocados na seguinte equação ${ }^{17}$ :

$$
\begin{aligned}
& 100-[(Q .4+Q .5+Q .8+Q .10-4) / 16] \times 100= \\
& =\text { domínio sócio-emocional }
\end{aligned}
$$

Já o domínio funcionamento físico envolve as questões 1 (Tenho dificuldade em falar forte ou ser ouvido em ambiente ruidoso), 2 (O ar acaba rápido e preciso respirar muitas vezes enquanto falo), 3 (Não sei como a voz vai sair quando começo a falar), 6 (Tenho dificuldades ao telefone por causa da minha voz), 7 (Tenho problemas no meu trabalho ou para desenvolver a minha profissão por causa da voz), 9 (Tenho que repetir o que falo para ser compreendido) inseridos no algoritmo: 
$100-[(Q .1+Q .2+Q .3+Q .6+Q .7+Q .9-6) / 24] x$ x 100 = domínio funcionamento físico

Finalmente, o domínio global inclui os itens 1 a 10 na equação:

$100-[(\mathrm{Q} .1+\mathrm{Q} .2+\mathrm{Q} .3+\mathrm{Q} .4+\mathrm{Q} .5+\mathrm{Q} .6+\mathrm{Q} .7+\mathrm{Q} .8+$

$+Q .9+Q .10-10) / 40] \times 100=$ domínio global

\section{Avaliação Fonoaudiológica}

Para a avaliação fonoaudiológica foi solicitado que os professores, em pé, expusessem um assunto referente à(s) disciplina(s) por eles ministradas na universidade. Seus discursos foram filmados e posteriormente avaliados nos aspectos corporais e vocais ${ }^{19}$, sendo cada item classificado quanto à presença ou ausência de alterações. Os aspectos corporais abrangeram e foram classificados em: postura (ajustada ou restrita), gestos (equilibrados ou restritos), o contato visual (equilibrado ou restrito). Já os aspectos vocais incluíram: pitch (adequado, grave ou agudo), loudness (forte, média ou fraca), projeção (suficiente ou insuficiente), modulação (adequada ou restrita), qualidade vocal (adaptada, rouca, infantilizada, monótona, dentre outras), velocidade de fala (adequada, acelerada ou lentificada), articulação (bem definida ou mal-definida) e coordenação pneumofônica (suficiente ou insuficiente). Quando presente, a disfonia foi avaliada nos seguintes graus: discreto, moderado, severo e extremo.

Esta pesquisa recebeu aprovação do Comitê de Ética em Pesquisa da PUC-Campinas sob o número 427/04 em 02/12/04.

Os dados foram analisados unicamente por meio da estatística descritiva e os resultados expressos em valores numéricos e percentuais e abordaram: a auto-avaliação dos professores às suas vozes, escores de cada sujeito e média do conjunto deles nos três domínios previstos pelo instrumento, frequências e respectivas porcentagens obtidas em cada questão do QVV e presença e ausência de alteração nos parâmetros constituintes da avaliação fonoaudiológica. Posteriormente, os resultados do QVV e da avaliação fonoaudiológica de alguns professores foram comparados qualitativamente, de modo a salientar singularidades de interesse do estudo.

\section{RESULTADOS}

$\mathrm{Na}$ auto-avaliação vocal, verificou-se que nove $(2,85 \%)$ deles avaliaram suas vozes como boa, sete $(33,3 \%)$ como razoável, três $(9,54 \%)$ como ruim e apenas dois $(9,52 \%)$ como muito boa, conforme Tabela 1.
Tabela 1 - Auto-avaliação vocal dos professores

\begin{tabular}{lccc}
\hline Resposta & Escore & Frequência & $\%$ \\
\hline Excelente & 1 & 0 & 0 \\
Muito Boa & 2 & 2 & 9,5 \\
Boa & 3 & 9 & 42,8 \\
Razoável & 4 & 8 & 38,1 \\
Ruim & 5 & 2 & 9,5 \\
Total & & 21 & 100 \\
\hline
\end{tabular}

Especificamente em relação aos domínios abarcados pelo QVV (Tabela 2), o sócio-emocional apresentou média de 88,98 (100 a 56,28), o funcionamento físico 78,18 (100 a 41,67).

Nos resultados dos escores obtidos pelos professores individualmente (Tabela 3), as dificuldades localizam-se mais no processo de produção da voz, como dificuldade em falar forte ou ser ouvido em ambientes ruidosos ( $N=11,52,37 \%)$, uma possível falta de inteligibilidade da voz para o interlocutor $(\mathrm{N}=4,19,04 \%)$, descontrole do ar $(\mathrm{N}=3,14,3 \%)$ e encontrar problemas no trabalho e para desenvolver a profissão por causa da voz ( $\mathrm{N}=4,19,04 \%)$.

No escopo do domínio sócio-emocional, as questões mais relevantes foram: estar ansioso ou frustrado por causa da voz $(\mathrm{N}=6,28,56 \%)$ e ficar deprimido por causa da voz $(\mathrm{N}=4,19,04 \%)$, como mostra a Tabela 3.

No Domínio Global, os escores obtidos variaram de 100 a 60, com média de 82,61. A totalidade dos professores alcançou escores acima de 60 , sendo que nove $(42,8 \%)$ deles entre $60-80$ e $12(57,2 \%)$ entre 81-100, conforme Tabela 3.

Quanto à avaliação fonoaudiológica, a Tabela 4 mostra a análise descritiva dos resultados obtidos nos itens que compuseram a análise corporal e vocal dos professores pesquisados como grupo. Destaca-se que na primeira, a alteração mais frequente foi a tensão em $10(47,61 \%)$ docentes e, na segunda, os destaques foram para a restrição da modulação vocal em 11 (52,38\%) professores e projeção vocal em 10 (47,61\%) deles.

A comparação dos resultados individuais do QVV e da avaliação fonoaudiológica mostrou-se de interesse, pois embora a média dos domínios do primeiro instrumento tenham sido altas, as alterações dos aspectos corporais e vocais ocorreram em oito $(38,09 \%)$ dos participantes, com diferentes impactos sobre a qualidade de vida deles (Tabela 5). 
Tabela 2 - Respostas dos professores ao QVV com escores, frequência e porcentagem

\begin{tabular}{|c|c|c|c|c|}
\hline Questões & Respostas & Escore & Freq. & $\%$ \\
\hline \multirow{5}{*}{$\begin{array}{l}\text { 1. Tenho dificuldade em } \\
\text { falar forte (alto) ou ser } \\
\text { ouvido em ambientes } \\
\text { ruidosos }\end{array}$} & Nunca acontece e não é um problema & 1 & 3 & 14,3 \\
\hline & Acontece pouco e raramente é um problema & 2 & 7 & 33,3 \\
\hline & Acontece às vezes e é um problema moderado & 3 & 6 & 28,5 \\
\hline & Acontece muito e quase sempre é um problema & 4 & 4 & 19 \\
\hline & Acontece sempre e realmente é um problema & 5 & 1 & 4,8 \\
\hline \multirow{5}{*}{$\begin{array}{l}\text { 2. O ar acaba rápido e } \\
\text { preciso respirar muitas } \\
\text { vezes enquanto eu falo }\end{array}$} & Nunca acontece e não é um problema & 1 & 11 & 52,4 \\
\hline & Acontece pouco e raramente é um problema & 2 & 7 & 33,3 \\
\hline & Acontece às vezes e é um problema moderado & 3 & 1 & 4,8 \\
\hline & Acontece muito e quase sempre é um problema & 4 & 2 & 9,5 \\
\hline & Acontece sempre e realmente é um problema & 5 & 0 & 0 \\
\hline \multirow{5}{*}{$\begin{array}{l}\text { 3. Não sei como a voz vai } \\
\text { sair quando começo a } \\
\text { falar }\end{array}$} & Nunca acontece e não é um problema & 1 & 11 & 52,4 \\
\hline & Acontece pouco e raramente é um problema & 2 & 6 & 28,5 \\
\hline & Acontece às vezes e é um problema moderado & 3 & 2 & 9,5 \\
\hline & Acontece muito e quase sempre é um problema & 4 & 2 & 9,5 \\
\hline & Acontece sempre e realmente é um problema & 5 & 0 & 0 \\
\hline \multirow{5}{*}{$\begin{array}{l}\text { 4. Fico ansioso ou } \\
\text { frustrado (por causa da } \\
\text { minha voz) }\end{array}$} & Nunca acontece e não é um problema & 1 & 10 & 47,6 \\
\hline & Acontece pouco e raramente é um problema & 2 & 5 & 23,8 \\
\hline & Acontece às vezes e é um problema moderado & 3 & 3 & 14,3 \\
\hline & Acontece muito e quase sempre é um problema & 4 & 3 & 14,3 \\
\hline & Acontece sempre e realmente é um problema & 5 & 0 & 0 \\
\hline \multirow{5}{*}{$\begin{array}{l}\text { 5. Fico deprimido (por } \\
\text { causa da minha voz ) }\end{array}$} & Nunca acontece e não é um problema & 1 & 16 & 76,2 \\
\hline & Acontece pouco e raramente é um problema & 2 & 1 & 4,8 \\
\hline & Acontece às vezes e é um problema moderado & 3 & 4 & 19 \\
\hline & Acontece muito e quase sempre é um problema & 4 & 0 & 0 \\
\hline & Acontece sempre e realmente é um problema & 5 & 0 & 0 \\
\hline \multirow{5}{*}{$\begin{array}{l}\text { 6. Tenho dificuldades ao } \\
\text { telefone (por causa da } \\
\text { minha voz) }\end{array}$} & Nunca acontece e não é um problema & 1 & 14 & 66,7 \\
\hline & Acontece pouco e raramente é um problema & 2 & 7 & 33,3 \\
\hline & Acontece às vezes e é um problema moderado & 3 & 0 & 0 \\
\hline & Acontece muito e quase sempre é um problema & 4 & 0 & 0 \\
\hline & Acontece sempre e realmente é um problema & 5 & 0 & 0 \\
\hline \multirow{5}{*}{$\begin{array}{l}\text { 7. Tenho problemas } \\
\text { no meu trabalho ou para } \\
\text { desenvolver minha } \\
\text { profissão (por causa } \\
\text { da voz) }\end{array}$} & Nunca acontece e não é um problema & 1 & 9 & 42,8 \\
\hline & Acontece pouco e raramente é um problema & 2 & 8 & 38 \\
\hline & Acontece às vezes e é um problema moderado & 3 & 1 & 4,8 \\
\hline & Acontece muito e quase sempre é um problema & 4 & 3 & 14,3 \\
\hline & Acontece sempre e realmente é um problema & 5 & 0 & 0 \\
\hline \multirow{5}{*}{$\begin{array}{l}\text { 8. Evito sair socialmente } \\
\text { (por causa da voz) }\end{array}$} & Nunca acontece e não é um problema & 1 & 21 & 100 \\
\hline & Acontece pouco e raramente é um problema & 2 & 0 & 0 \\
\hline & Acontece às vezes e é um problema moderado & 3 & 0 & 0 \\
\hline & Acontece muito e quase sempre é um problema & 4 & 0 & 0 \\
\hline & Acontece sempre e realmente é um problema & 5 & 0 & 0 \\
\hline \multirow{5}{*}{$\begin{array}{l}\text { 9. Tenho que repetir o } \\
\text { que falo para ser } \\
\text { compreendido }\end{array}$} & Nunca acontece e não é um problema & 1 & 6 & 25,8 \\
\hline & Acontece pouco e raramente é um problema & 2 & 12 & 57,1 \\
\hline & Acontece às vezes e é um problema moderado & 3 & 3 & 14,3 \\
\hline & Acontece muito e quase sempre é um problema & 4 & 0 & 0 \\
\hline & $\begin{array}{l}\text { Acontece sempre e realmente } \\
\text { é um problema }\end{array}$ & 5 & 0 & 0 \\
\hline \multirow{5}{*}{$\begin{array}{l}\text { 10. Tenho me tornado } \\
\text { menos expansivo (por } \\
\text { causa da minha voz) }\end{array}$} & Nunca acontece e não é um problema & 1 & 15 & 71,4 \\
\hline & Acontece pouco e raramente é um problema & 2 & 4 & 19 \\
\hline & Acontece às vezes e é um problema moderado & 3 & 2 & 9,5 \\
\hline & Acontece muito e quase sempre é um problema & 4 & 0 & 0 \\
\hline & Acontece sempre e realmente é um problema & 5 & 0 & 0 \\
\hline
\end{tabular}


Tabela 3 - Análise descritiva dos escores obtidos pelos professores nos domínios do QVV

\begin{tabular}{cccc}
\hline Professor & Sócio-Emocional & Funcionamento Físico & Global \\
\hline P1 & 100 & 100 & 100 \\
P2 & 87,5 & 41,67 & 62,5 \\
P3 & 93,75 & 83,4 & 87,5 \\
P4 & 93,75 & 91,67 & 92,5 \\
P5 & 100 & 87,5 & 92,5 \\
P6 & 62,5 & 58,4 & 60 \\
P7 & 56,25 & 70,9 & 65 \\
P8 & 87,5 & 62,5 & 72,5 \\
P9 & 100 & 87,5 & 92,5 \\
P10 & 100 & 95,83 & 97,5 \\
P11 & 93,75 & 58,33 & 72,5 \\
P12 & 68,75 & 62,5 & 65 \\
P13 & 100 & 95,84 & 97,5 \\
P14 & 100 & 79,16 & 87,5 \\
P15 & 100 & 87,5 & 92,5 \\
P16 & 81,25 & 62,5 & 70 \\
P17 & 87,5 & 70,83 & 77,5 \\
P18 & 62,5 & 79,16 & 72,5 \\
P19 & 100 & 91,66 & 95 \\
P20 & 93,75 & 87,5 & 90 \\
P21 & 100 & 87,5 & 92,5 \\
Média & 88,98 & 78,18 & 82,61 \\
\hline & & &
\end{tabular}

Tabela 4 - Presença ou ausência de alteração na avaliação fonoaudiológica dos professores

\begin{tabular}{lcccc}
\hline \multirow{2}{*}{ Aspecto Avaliado } & \multicolumn{2}{c}{ Adequado } & \multicolumn{2}{c}{ Alterado } \\
\cline { 2 - 5 } & $\mathbf{N}$ & $\%$ & $\mathbf{N}$ & $\%$ \\
\hline Postura Corporal & 15 & 71,42 & 6 & 28,57 \\
Gestos & 14 & 66,66 & 7 & 33,33 \\
Contato Visual & 15 & 71,42 & 6 & 28,57 \\
Tensão & 11 & 52,38 & 10 & 47,61 \\
Pitch & 17 & 80,95 & 4 & 19,04 \\
Loudness & 17 & 80,95 & 4 & 19,04 \\
Projeção Vocal & 11 & 52,38 & 10 & 47,61 \\
Modulação Vocal & 10 & 47,61 & 11 & 52,38 \\
Velocidade de Fala & 21 & 100 & 0 & 0 \\
Qualidade Vocal & 14 & 66,66 & 7 & 33,33 \\
Articulação & 20 & 95,23 & 1 & 4,76 \\
Coordenação entre a respiração e fonação & 14 & 66,66 & 7 & 33,33 \\
\hline
\end{tabular}


Tabela 5 - Comparação entre os resultados do QVV e a avaliação fonoaudiológica

\begin{tabular}{|c|c|c|c|c|c|c|c|c|}
\hline Prof. & Sexo & Idade & AAVocal & DSE & DFF & Global & Impacto & Av. Fonoaud. \\
\hline $\mathrm{P} 1$ & $\mathrm{~F}$ & 58 & muito boa & 100 & 100 & 100 & baixo & adaptada \\
\hline P2 & $\mathrm{F}$ & 72 & ruim & 87,5 & 41,67 & 62,5 & médio & $\begin{array}{c}\text { rouca e trêmula grau } \\
\text { moderado }\end{array}$ \\
\hline P3 & $M$ & 48 & razoável & 93,75 & 83,4 & 87,5 & baixo & adaptada \\
\hline P4 & $\mathrm{F}$ & 33 & boa & 93,75 & 91,67 & 92,5 & baixo & adaptada \\
\hline P5 & $\mathrm{F}$ & 46 & boa & 100 & 87,5 & 92,5 & baixo & adaptada \\
\hline P6 & $\mathrm{F}$ & 53 & razoável & 62,5 & 58,4 & 60 & alto & monótona \\
\hline P7 & $\mathrm{F}$ & 53 & razoável & 56,25 & 70,9 & 65 & médio & monótona \\
\hline P8 & $\mathrm{F}$ & 42 & razoável & 87,5 & 62,5 & 72,5 & médio & rouca grau leve \\
\hline P9 & $F$ & 30 & boa & 100 & 87,5 & 92,5 & baixo & adaptada \\
\hline P10 & $\mathrm{F}$ & 51 & boa & 100 & 95,83 & 97,5 & baixo & adaptada \\
\hline $\mathrm{P} 11$ & $\mathrm{~F}$ & 60 & razoável & 93,75 & 58,33 & 72,5 & médio & monótona \\
\hline $\mathrm{P} 12$ & $\mathrm{~F}$ & 46 & razoável & 68,75 & 62,5 & 65 & médio & rouco -soprosa grau severo \\
\hline $\mathrm{P} 13$ & M & 36 & boa & 100 & 95,84 & 97,5 & baixo & adaptada \\
\hline P14 & $\mathrm{F}$ & 48 & boa & 100 & 79,16 & 87,5 & baixo & adaptada \\
\hline $\mathrm{P} 15$ & M & 50 & muito boa & 100 & 87,5 & 92,5 & baixo & adaptada \\
\hline P16 & M & 24 & razoável & 81,25 & 62,5 & 70 & médio & monótona \\
\hline $\mathrm{P} 17$ & $\mathrm{~F}$ & 48 & razoável & 87,5 & 70,83 & 77,5 & médio & rouca grau leve \\
\hline $\mathrm{P} 18$ & $\mathrm{~F}$ & 47 & ruim & 62,5 & 79,16 & 72,5 & médio & adaptada \\
\hline P19 & $\mathrm{F}$ & 48 & boa & 100 & 91,66 & 95 & baixo & adaptada \\
\hline $\mathrm{P} 20$ & M & 42 & boa & 93,75 & 87,5 & 90 & baixo & adaptada \\
\hline $\mathrm{P} 21$ & $\mathrm{~F}$ & 42 & boa & 100 & 87,5 & 92,5 & baixo & adaptada \\
\hline
\end{tabular}

Legenda: AA Vocal - Auto Avaliação vocal

DSE - Domínio Sócio Emocional

DFF - Domínio Funcionamento Físico

\section{DISCUSSÃO}

$\mathrm{Na}$ auto-avaliação vocal realizada pelos professores participantes nenhum deles classificou sua voz como excelente, sendo que a maior parte deles atribuiu-Ihes o conceito de boa ou muito boa (52,3\%), porém a porcentagem que usou a classificação razoável ou ruim também foi relevante $(47,6 \%)$. Professores de outros estudos também auto avaliaram suas vozes como boas ou muito boas ${ }^{14,16,20}$, porém seus autores justificam que este julgamento ocorreu devido à dificuldade desses docentes em perceberem o impacto da voz nas atividades diárias, exceto quando ela já apresenta grau severo de alteração. Isto diverge dos resultados da presente pesquisa, pois as avaliações vocais referidas como razoável e ruim apresentaram valores significativos, concordando com outro autor que afirma que os professores universitários demonstram conhecimento de suas vozes ${ }^{21}$.

Em relação aos domínios abarcados pelo QVV, o sócio-emocional apresentou média de escores maior que o domínio do funcionamento físico, evidenciando que o impacto da voz é maior neste último nível, alterando a qualidade de vida para pior, conforme achados de outros estudos ${ }^{22,23}$.

Nos resultados dos escores individuais dos professores, os valores do domínio sócio-emocional quase sempre superaram os do funcionamento físico, o que corrobora as conclusões de outras pesquisas que utilizaram o mesmo instrumento ${ }^{14,17,18}$. Sobressaem as respostas dos professores assinaladas no QVV relativas a sentir dificuldades em falar forte em ambientes ruidosos, o que pode indicar falta de qualificação docente para contornar a necessidade de falar em presença de ruído, situação tão usual na docência.

No domínio sócio-emocional, as questões mais relevantes relacionam-se a estar ansioso ou frustrado por causa da voz e ficar deprimido por causa da voz. Contudo os sujeitos mostraram por suas respostas ao questionário que não se afastam de situações sociais e interativas e não exibem sentimentos de frustração, ansiedade e depressão devido a sua voz, resultados concordantes com os de outros estudos ${ }^{14,18}$. A voz é relevante para o 
professor encontrar realização pessoal e profissional nas relações sociais ${ }^{19}$ e nesta pesquisa, essa importância da voz ficou evidenciada pelos escores obtidos nesse domínio do QVV.

Pelo exposto, verifica-se que os professores indicam mais problemas com o controle de ar, com a articulação e volume de voz, inerentes ao funcionamento físico, importantes para o emprego da voz na docência, do que com frustrações, ansiedades e depressões por causa da voz, mais pertinentes ao nível sócio-emocional. Oportunizar aos docentes um trabalho de assessoria vocal pode resultar na superação de dificuldades vocais por proporcionar melhor controle da voz e seu uso eficaz na docência ${ }^{1,6,9}$.

A análise global das respostas dos professores mostra que grande parte deles apresenta alguma queixa ligada à voz e que pode interferir negativamente em seu desenvolvimento profissional. Esta questão merece ser valorizada quando se considera todo o tempo e investimentos empregados para a qualificação de um bom professor. A restrição de trabalho gerada por um distúrbio da voz pode prejudicar a qualidade das aulas, interferir na aprendizagem dos alunos e até comprometer a carreira e a saúde do docente ${ }^{3,6}$.

No Domínio Global, as médias dos escores obtidos foram altas e similares ${ }^{18,22}$ ou maiores ${ }^{22}$ quando comparadas com aquelas decorrentes de investigações do mesmo tipo.

Tudo isso permite considerar que o impacto da voz sobre a qualidade de vida é baixo para os professores da presente pesquisa, porém a diferença entre os escores dos domínios (físico e social) requer medidas de atenção e promoção da saúde com o objetivo de integrar os aspectos envolvidos nos domínios e obter melhor qualidade de vida para os professores.

$\mathrm{Na}$ avaliação fonoaudiológica dos professores constatou-se que no aspecto corporal, as maiores dificuldades foram a tensão da região cervical e o uso restrito dos gestos, uma vez que o eixo corporal e o contato visual estavam apropriados. Especificamente em relação à voz, dos 21 professores, 13 $(61,90 \%)$ vozes foram avaliadas como adaptadas e oito $(38,09 \%)$ como alteradas, sendo destas $50 \%$ monótonas (P6, P7, P11 e P16) e 50\% roucas, duas em grau leve (P8 e P17), uma em severo (P12) e outra em grau moderado, acompanhada de tremor (P2).

A projeção e modulação vocais reduzidas podem estar associadas à idade das professoras, pois três delas estão acima de 50 anos, faixa etária compatível com a menopausa ${ }^{24}$. A rouquidão, por outro lado, usualmente, associada ao emprego abusivo da voz e compatível com as condições adversas da docência, mostra-se presente $3,5,18$ naqueles docentes em pleno desenvolvimento profissional. Apenas no docente que exibe rouquidão acompanhada de tremor pode-se inferir a presença de alguma doença mais séria, associada a faixa etária. Em qualquer dos casos, a orientação vocal propiciaria maior desenvolvimento da ressonância, riqueza entonacional e potencialidades vocais dos docentes, e minimizaria os distúrbios mais graves ${ }^{25}$.

O uso restrito de gestos durante a exposição do conteúdo instrucional, combinado com falta de projeção e modulação vocal pode explicar a tensão excessiva da região cervical e reforçam a alta frequência de queixas quanto à dificuldade de falar forte ou ser ouvido em ambientes ruidosos, referidas pelos professores. Sem dispor da técnica que favoreça o uso apropriado da voz, a tendência é o abuso vocal que vai, ao longo do tempo, gerando danos à laringe e disfonia ${ }^{26,27}$.

A comparação entre a avaliação fonoaudiológica e a avaliação vocal auto referida pelos docentes mostrou concordância em 19 (90,47\%) vozes, das quais $11(57,89 \%)$ foram consideradas adaptadas pelos fonoaudiólogos e muito boas (2) e boas (9) pelos docentes; e oito $(42,10 \%)$ delas qualificadas como monótonas ou roucas e ruim (1) e razoável (7), respectivamente por fonoaudiólogos e professores. Houve discordância em duas $(9,52 \%)$ das vozes, pois os docentes classificaram-nas como razoável e ruim e o fonoaudiólogo considerou-as sem alterações.

Comparando-se a avaliação vocal realizada pelo professor, a avaliação fonoaudiológica e os escores obtidos no QVV, constata-se que em 11 $(52,38 \%)$ vozes houve a convergência entre as qualificações muito boa e boa (oriundas dos docentes), vozes adaptadas (segundo a fonoaudióloga), e baixo impacto sobre a qualidade de vida e voz (decorrentes dos escores altos). Da mesma forma, houve coincidência em seis vozes $(28,57 \%)$ avaliadas como razoáveis pelos docentes, monótona ou rouca e escores mais baixos com consequente impacto médio sobre a qualidade de vida. Uma $(4,76 \%)$ voz foi considerada razoável, monótona e com alto impacto na qualidade de vida e outra avaliada como ruim, disfonia em grau severo e impacto médio sobre a qualidade de vida, estando professor e fonoaudiólogo em consonância. O desacordo ocorreu em uma única voz considerada ruim pelo professor e adaptada pelo fonoaudiólogo com impacto médio sobre a qualidade de vida.

Pelo exposto, observa-se avaliação consensual entre a avaliação do professor pelo QVV e a avaliação fonoaudiológica e indica que os docentes participantes do presente estudo souberam proceder à qualificação de suas vozes, quando elas estavam 
alteradas ou não, em simetria com alguns estudos ${ }^{21}$ e contrariando outros ${ }^{18,20}$.

Constataram-se diferenças e similaridades entre os escores obtidos com os professores universitários desse estudo e aqueles docentes de pesquisas com outros níveis de ensino ${ }^{17,18,22}$. Os primeiros, de modo geral, apresentam maiores escores e, com isso, menor impacto da voz sobre a qualidade de vida. Este fato, certamente, demanda várias considerações, entre elas, as melhores condições de vida, menor carga horária diária de trabalho, condições físicas de trabalho mais estruturadas e até que a voz se constitua apenas um dentre os muitos parâmetros para se avaliar a qualidade de vida em professores. Foge do escopo desta pesquisa esclarecer esta questão, contudo abre perspectivas para novos estudos nesta área.

\section{CONCLUSÃO}

Os resultados da pesquisa permitem concluir que a voz apresenta baixo impacto na qualidade de vida dos professores universitários deste estudo e que o domínio mais comprometido foi o físico, no qual a dificuldade em falar alto ou ser ouvido em ambientes ruidosos e ter problemas no trabalho ou desenvolver a profissão por causa da voz são os mais expressivos.

A comparação entre os achados do QVV e da avaliação fonoaudiológica exibiram mais aspectos concordantes que discordantes, indicativo de que os professores desse estudo souberam avaliar de forma apropriada suas vozes e o impacto das mesmas sobre a qualidade de vida.

\begin{abstract}
Purpose: to investigate the voice impact on life quality of teachers and compare results with the Speech-Language evaluation. Methods: 21 university teachers took part, $77 \%$ women and $23 \%$ men, with mean age of 48 years, who filled in the Quality of Life and Voice Protocol (QLV), and were shot for the Speech-Language evaluation in the body and vocal aspects. Results: the docents classified their voices as good $(42.85 \%)$, reasonable $(38.09 \%)$ and very good and bad, equally $(9.52 \%)$. The Physical Domain showed average score: 78.18 , highlighting the difficulty of speaking loud or being listened in noisy environments, problems at work or to develop career because of voice. In the SocialEmotional Domain the average score was 88.98 and showed anxiety or frustration due to voice. The Global Domain had an average of 82.61. In the Speech-Language evaluation more adapted $(61.90 \%)$ than altered $(38.09 \%)$ voices were noted, with these last ones showing restriction in projection and modulation or hoarseness. The comparison among vocal self-evaluation, Speech-Language evaluation and life quality showed more consensus than divergences. Conclusion: it is concluded that the voice impact on the life quality was low and there was consistency between QLV results and Speech-Language evaluation, indicating appropriate perception from the docents of their own voices. The QLV showed predictive value in the relation between voice and life quality and can be indicated as a valuable instrument when utilized along with other research strategies.
\end{abstract}

KEYWORDS: Voice Disorders; Faculty; Quality of Life

\section{REFERÊNCIAS}

1. Fuess VLR, Lorenz MC. Disfonia em professores do ensino municipal: prevalência e fatores de risco. Rev Bras Otorrinolaringol. 2003; 69(6):807-12.

2. Roy N, Merrill RM, Thibeault S, Parsa RA, Gray SD, Smith EM. Prevalence of voice disorders in teachers and the general population. J Speech Lang Hear Res. 2004; 47(2):281-93.

3. Kooijman PG, Jong FI, Thomas G, Huinck W, Donders R, Graamans K, et al. Risk factors for voice problems in teachers. Folia Phoniatric Logop. 2006; 58(3):159-74.
4. Skarlatos D, Manatakis M. Effects of classroom noise on students and teachers in Greece. Percept Motor Skills. 2003; 96(2):539-44.

5. Secretaria de Estado de Saúde de São Paulo. Distúrbios da voz relacionados ao trabalho. Boletim Epidemiológico Paulista. 2006; 3(26):16-22

6. Ferreira LP, Giannini SPP, Figueira S, Silva EE, Karmann DF, Souza TMT. Condições de produção vocal de professores da prefeitura do município de São Paulo. Dist Comun. 2003; 14(2):275-307.

7. Souza OC, Hanayama EM. Fatores psicológicos associados a disfonia funcional e a nódulos vocais em adultos. Rev CEFAC. 2005; 7(3):388-97. 
8. Garcia LP. Benevides-Pereira AMT. Investigando o burnout em professores universitários. [periódico online] Rev Eletrônica InterAção Psy. 2003; 1(1):7689. Disponível em: URL: http://www.saudeetrabalho. com.br/download_2/burnout-prof-universitario.pdf

9. Carelli EG, Nakao M. Educação vocal na formação do docente. Fono Atual. 2002; 5(22):40-52.

10. Brasil. Ministério da Saúde. Promoção da Saúde. Brasília (DF); 2001.

11. Buss PM. Promoção de saúde e qualidade de vida. Ciênc Saúde Colet. 2000; 5(1):163-77.

12. Declaração de Jacarta. A declaração de Jacarta sobre promoção da saúde pelo século XXI adentro. Relatório da $4^{\mathrm{a}}$ Conferência Internacional sobre Promoção da Saúde. Jacarta. Indonésia, 21-25 de julho de 1997.

13. Seildl EF, Zannon CML. Qualidade de vida e saúde: aspectos conceituais e metodológicos. Cad Saúde Públ. 2004; 20(2):580-8.

14. Penteado RZ, Pereira IMTB. Avaliação do impacto da voz na qualidade de vida de professores. Rev Bras Fonoaudiol. 2003; 8(2):19-28.

15. Hogikyan ND, Sethuraman G. Validation of an instrument to measure voice-related quality of life (V-RQOL). J Voice. 1999; 13(4):557-69.

16. Behlau M. Qualidade de vida e voz: um estudo brasileiro. IX Congresso Brasileiro de Fonoaudiologia. 2001 Set 26-29 Guarapari, Espírito Santo. [CD-Rom].

17. Penteado RZ. Aspectos de qualidade de vida e subjetividade na promoção da saúde vocal de professores [tese]. São Paulo (SP): Universidade de São Paulo; 2003.
18. Grillo MHMM, Penteado RZ. Impacto da voz na qualidade de vida de professore(a)s do ensino fundamental. Pró-Fono. 2005; 17(3):321-30.

19. Behlau M, Damázio G, Feijó D, Pontes P. Avaliação de voz. In: Behlau M. (org.) Voz. O livro do especialista. vol I. Rio de Janeiro: Revinter; 2001. p. $85-180$

20. Penteado RZ, Pereira IMTB. Qualidade de vida e saúde vocal de professores. Rev Saúde Públ. 2007; 41(2):236-43.

21. Servilha EAM. Concepções sobre a voz na docência presentes nos discursos de professores universitários. XIII Congresso Brasileiro de Fonoaudiologia. 2005 Set 28-30 Santos, SP. [CD-ROM]. 22. Murry T, Medrado R, Hogikyan ND, Aviv JE. The relationship between ratings of voice quality and quality of life measures. J Voice. 2004; 18(2):183-92.

23. Kasama ST, Brasolotto AG. Percepção vocal e qualidade de vida. Pró-Fono. 2007; 19(1):19-28.

24. Behlau M, Rehder MI, Valente O. Disfonias endócrinas. In: Behlau M, organizador. Voz: o livro do especialista. vol 2. Rio de Janeiro: Revinter; 2005. p. 51-78.

25. Escalona E. Programa para la preservación de la voz en docentes de educación básica. Salud Trabaj. 2006; 14(1):31-49.

26. Garcia AA. Vivências corporais-vocais: prática preventiva. In: Ferreira LP, Andrada e Silva MA. Saúde vocal. Práticas fonoaudiológicas. São Paulo: Roca; 2002. p.7-17.

27. Bovo R, Galceran M, Petruccelli J, Hatzopoulos S. Vocal problems among teachers: evaluation of a preventive voice program. J Voice. 2007; 21(6):705-22.

DOI: 10.1590/S1516-18462009005000029

RECEBIDO EM: 26/03/2008

ACEITO EM: 23/01/2009

Endereço para correspondência:

Emilse Aparecida Merlin Servilha

Av Palomino, 371

Salto - SP

CEP: 13324-311

E-mail: emilsemerlin@uol.com.br 